\title{
Avaliação em larga escala e educação especial inclusiva: 0 embate entre duas lógicas
}

\author{
Large-scale assessment and inclusive special education: the clash between \\ two logics
}

Evaluación a gran escala y educación especial inclusiva: el choque entre dos lógicas

\author{
Erika Marinho Witeze \\ Professora do Instituto Federal de Educação, Ciência e Tecnologia de Goiás, Anápolis, Goiás, Brasil. \\ erikawiteze@gmail.com \\ ORCID - https://orcid.org/0000-0002-5757-0229 \\ Régis Henrique dos Reis Silva \\ Professor doutor da Universidade Estadual de Campinas, Campinas, São Paulo, Brasil. \\ regishsilva@gmail.com \\ ORCID - https://orcid.org/0000-0001-6392-0697
}

Recebido em 24 de agosto de 2019

Aprovado em 12 de novembro de 2019

Publicado em 12 de dezembro de 2019

\section{RESUMO}

O artigo discute os embates entre as políticas de educação especial na perspectiva inclusiva e as políticas de avaliação da educação básica. Nós analisamos a escola da rede estadual de Goiás com as maiores médias no Índice de Desenvolvimento da Educação Básica - considerando as primeiras cinco edições do exame nacional. $O$ estudo se concentra nos fatores envolvidos na participação do público-alvo da educação especial na Prova Brasil e problematiza as contradições expressas no confronto entre as políticas inclusivas e a lógica neotecnicista, que orienta as avaliações em larga escala no contexto neoliberal. Os métodos foram: análise documental/bibliográfica; observação participante das rotinas escolares; entrevistas semiestruturadas com gestores, coordenadores pedagógicos, profissionais de apoio à inclusão e professores de recursos. A partir dos dados coletados evidenciamos a coexistência de processos de inclusão/exclusão, resultantes da utilização da Prova Brasil como instrumento de aferição do desempenho de alunos com necessidades educacionais especiais em áreas específicas do currículo. Nossas análises certificaram que a abordagem neotecnicista interfere nas formas de organização do trabalho educativo da escola e na definição dos conteúdos curriculares que serão ministrados pelos professores, em conformidade com as metas definidas pelo Ministério da Educação, pelas agências multilaterais e pelo próprio governo do estado de Goiás. De acordo com os resultados da pesquisa, o ambiente escolar emerge, pois, como espaço de tensão entre diferentes projetos de formação humana, no qual o respeito à diversidade é suplantado pela perspectiva pragmática, mercadológica e classificatória difundida pelos testes padronizados.

Palavras-chave: Educação especial inclusiva; Avaliação em larga escala; Políticas de inclusão. 
http://dx.doi.org/10.5902/1984686X39687

\section{ABSTRACT}

This paper discuss the clashes between the special education policies on inclusive perspective and the basic education evaluation policies. We analyze the Goiás state school with the highest averages on Development Basic Education Index - considering the first five editions of the national exam. The study focused on the factors involved in the participation of the target audience of special education in Proof Brasil. We explore the contradictions expressed in the conflict between inclusive policies and neotechnicist logic, which guides the large scale evaluations in the neoliberal context. The research had several fases: documental and bibliographical analyzes; participant observation of the school routines; semi-structured interviews with managers, pedagogic coordinators, inclusion support professionals and special education teachers. The data revealed that Proof Brazil is used as an instrument to measure the performance of students with special needs in specific areas of the curriculum. As a result we see the coexistence of inclusion/exclusion process. The neotechnicist approach interferes in the school: it changes the forms of pedagogic organization and the curricular contents, according the goals defined by the Ministry of Education, the multilateral agencies and the Goiás State Government. We conclude: the school environment is space tensioned by two different projects of human formation and the respect to diversity is outshined by the pragmatic, marketing and classificatory perspective, which is widespread by standardized tests.

Keywords: Inclusive special education; Large scale evaluation; Inclusion policies.

\section{RESUMEN}

El artículo analiza los enfrentamientos entre las políticas de educación especial desde una perspectiva inclusiva y las políticas de evaluación de la educación básica. Analizamos la escuela estatal de Goiás con los promedios más altos en el Índice de Desarrollo de Educación Básica, considerando las primeras cinco ediciones del examen nacional. El estudio se centra en los factores involucrados en la participación del público-objetivo de la educación especial en la Prova Brasil y problematiza las contradicciones expresadas en la confrontación entre políticas inclusivas y lógica neotécnica, que guía las evaluaciones a gran escala en el contexto neoliberal. Los métodos fueron: análisis documental / bibliográfico; observación participante de las rutinas escolares; entrevistas semiestructuradas con gerentes, coordinadores pedagógicos, profesionales de apoyo a la inclusión y maestros de recursos. A partir de los datos recopilados, mostramos la coexistencia de procesos de inclusión / exclusión, como resultado del uso de la Prova Brasil como herramienta para medir el desempeño de los estudiantes con necesidades educativas especiales en áreas específicas del plan de estudios. Nuestros análisis han confirmado que el enfoque neotécnico interfiere con las formas en que se organiza el trabajo educativo de la escuela y con la definición del contenido curricular que será entregado por los maestros, de acuerdo con los objetivos establecidos por el Ministerio de Educación, las agencias multilaterales y el propio gobierno estatal de Goiás. Según los resultados de la investigación, el ambiente escolar emerge, por lo tanto, como un espacio de tensión entre los diferentes proyectos de formación humana, en el que el respeto a la diversidad es suplantado por la perspectiva pragmática, de mercado y de clasificación difundida por las pruebas estandarizadas.

Palabras clave: Educación especial iclusiva; Evaluación a gran escala; Políticas de inclusión. 
http://dx.doi.org/10.5902/1984686X39687

\section{Introdução}

A pesquisa de mestrado em educação aqui apresentada investigou os aspectos envolvidos na participação do público-alvo da educação especial ${ }^{1}$ na Prova Brasil. Foram analisados os dados de uma escola da rede estadual de Goiás pela perspectiva da educação inclusiva. Buscou-se, em linhas gerais, averiguar a relação entre 0 ranqueamento e a classificação dos estabelecimentos de ensino em escalas de rendimento e os processos de inclusão/exclusão de alunos com Necessidades Educacionais Especiais (NEEs), considerando a delimitação anunciada pela Política Nacional de Educação Especial na Perspectiva da Educação Inclusiva (BRASIL, 2008), pela Resolução CEE nº 07 (GOIÁS, 2006) e pelo Decreto 7.611 (BRASIL, 2011) - que dispõe sobre a educação especial e sobre o Atendimento Educacional Especializado (AEE) no Brasil.

Partindo da problemática supracitada, nosso trabalho foi estruturado com base na seguinte pergunta síntese: em que medida as práticas de diagnóstico e monitoramento das redes de ensino sugeridas pelo Sistema de Avaliação da Educação Básica (SAEB) contribuem para a emergência dos processos de inclusão e/ou exclusão de alunos com NEEs no contexto escolar? E mais especificamente, como a Avaliação Nacional do Rendimento Escolar (ANRESC) ou Prova Brasil influi na escolarização do público-alvo da educação especial em uma escola estadual de Goiás?

A Política Nacional de Educação Especial na Perspectiva da Educação Inclusiva (BRASIL, 2008) ressalta a centralidade da educação especial como componente que perpassa todos os níveis e modalidades de ensino. Nessa perspectiva, sugere a superação da exclusão consubstanciada na garantia do acesso de todos os estudantes à escola regular.

Levando em conta as atuais exigências no atendimento à diversidade, as políticas de inclusão pressupõem a equiparação das oportunidades e a inserção dos educandos com NEEs na escola regular, junto aos demais alunos. Conclui-se, logo, que eles devam participar das avaliações externas, na medida em que estas se tornam uma exigência a ser cumprida pelos sistemas de ensino e pelos estabelecimentos educacionais, devendo contar com a cooperação de todos os estudantes matriculados na rede.

A partir de questionamentos e hipóteses sobre a efetivação das políticas inclusivas no campo dos testes padronizados objetivamos, pois, analisar em que condições o 
http://dx.doi.org/10.5902/1984686X39687

público-alvo da educação especial (BRASIL, 2008) que engloba as pessoas com deficiências, transtornos globais de desenvolvimento (TGD) e altas habilidades/superdotação ${ }^{2}$ - têm realizado a Prova Brasil em uma escola da rede estadual de Goiás. Problematizamos, desta forma, as contradições observadas em campo, decorrentes do embate entre as políticas inclusivas e a lógica neotecnicista que orienta as avaliações em larga escala no contexto neoliberal (FREITAS, 2011; SAVIANI, 2013).

A escolha da Prova Brasil como base empírica de nossa pesquisa se justifica por sua abrangência nacional e por sua importância na atualidade como mecanismo de responsabilização das escolas e redes de ensino. Trata-se de uma avaliação censitária envolvendo os alunos de $4^{\text {a }}$ série $/ 5^{\circ}$ ano e $8^{\text {a }}$ série $/ 9^{\circ}$ ano do Ensino Fundamental das escolas (inicialmente situadas na área urbana) das redes municipal, estadual e federal, com o objetivo de ponderar a qualidade do ensino ministrado nas instituições públicas. $O$ exame bianual - composto por itens pertencentes a uma escala calibrada e previamente definida - visa aferir competências e habilidades desenvolvidas pelos alunos em Língua Portuguesa (com foco em leitura) e Matemática (com foco na resolução de problemas) ao final de cada etapa de estudos (BRASIL, 2009).

Vale lembrar que os resultados do exame integram o Índice de Desenvolvimento da Educação Básica (IDEB), que é referência para a definição dos padrões de qualidade a serem alcançados até o ano de 2021, em consonância com o Plano de Metas Compromisso Todos pela Educação (BRASIL, 2007). O exame, que integra o $\mathrm{SAEB}^{3}$, tem assumido um papel importante na formulação de diagnósticos sobre as escolas, no monitoramento das redes de ensino e no controle dos resultados em nível nacional.

Na perspectiva de Bonamino (2002), a relação qualidade-avaliação ganha força no Brasil a partir da década de 1990, em um cenário de "valorização" da educação decorrente de seu vínculo com a reconversão produtiva. Ela passa a ser vista, portanto, como pré-requisito para a participação das empresas e dos trabalhadores em um mercado internacional cada vez mais competitivo. No campo educacional, o controle é deslocado do processo para os resultados, ressaltando a importância dos testes padronizados como estratégia de regulação da qualidade do ensino. Isso está em conformidade com uma "agenda globalmente estruturada para a educação" (FREITAS, 2007, p. 147), que tem a Prova Brasil e IDEB como desdobramentos mais evidentes. 
http://dx.doi.org/10.5902/1984686X39687

Outro ponto a ser destacado se refere à consequente marginalização de determinados grupos e segmentos (como os alunos com NEEs), alinhada às novas formas de regulação da "qualidade" da educação básica (MICHELS, 2006; FREITAS, 2011) - questões que têm adquirido maior visibilidade no campo acadêmico, com destaque para os trabalhos recentemente publicados por Sousa (2018), Rebelo e Kassar (2018) e Mendes e D'Affonseca (2018).

Autores como Gatti (2013), Freitas (2011, 2012), Sordi (2012) e Freitas (2013) evidenciam a disseminação de práticas de ranqueamento das escolas, que são pressionadas pelo poder público a elevar, de forma contínua, o seu IDEB. Nessa perspectiva, ressaltamos o efeito controverso produzido pelo uso de painéis informativos das notas, que são fixados nas portas dos estabelecimentos de ensino de Goiás. Inicialmente pensados com estratégias de divulgação dos resultados das redes estadual e municipal nas avaliações externas, acabam por constranger as unidades cujo desempenho não se aproxima das metas estabelecidas pelos órgãos de controle (FREITAS, 2011; HORTA NETO, 2013).

Entende-se que a devolutiva da avaliação por meio de notas - o que sugere a formulação de rígidas escalas de classificação por desempenho - acaba não levando em consideração a diversidade de ritmos de aprendizagem, a multiplicidade de processos de ensino ou variações didáticas e as habilidades/competências desenvolvidas pelos educandos ao longo de seu período de escolarização, que não podem ser efetivamente mensuradas. Daí a necessidade de uma abordagem qualitativa - e não apenas quantitativa - do desempenho dos estudantes (FREITAS, 2011; GATTI, 2013).

A crescente adequação da escola à lógica do capital, o acirramento das desigualdades sociais e a consequente marginalização de determinados segmentos (entre eles os estudantes com NEEs) são alguns dos pontos de tensão que revelam as contradições constitutivas tanto ao paradigma da inclusão quanto das políticas de avaliação em larga escala - implementadas no Brasil a partir de 1990. Olhando para as estatísticas diríamos que há um esforço inédito para que todos estejam incluídos. Por outro lado, observando a terminalidade de cada um, vemos que os processos de exclusão se tornaram mais sutis, "colocados ao longo de uma cadeia educativa altamente piramidal” (FREITAS, 2004, p. 66). No caso do público-alvo da educação especial na perspectiva inclusiva, as contradições inerentes à lógica dos resultados se expressam de 
http://dx.doi.org/10.5902/1984686X39687

forma ainda mais aguda, tendo em vista as especificidades decorrentes das condições de aprendizagem às quais esse público é submetido.

\section{Metodologia de pesquisa}

Para que nossos objetivos fossem alcançados, a investigação foi organizada em duas etapas, ambas concluídas no ano de 2015. Na primeira realizamos uma revisão da literatura sobre o tema, buscando nos principais periódicos da última década ${ }^{4}$ artigos que abordassem a questão, além das teses e dissertações vinculadas direta e indiretamente ao assunto. Analisamos também as bases teóricas e legais das políticas de inclusão e avaliação em larga escala implementadas no Brasil, tendo como ferramentas de apoio a legislação disseminada em âmbito nacional, bem com as diretrizes que orientam as políticas inclusivas/avaliativas na rede estadual de Goiás. Concomitantemente, realizamos uma verificação das bases de dados oficiais divulgadas pelo Ministério da Educação (MEC), pelo Instituto Nacional de Pesquisas Educacionais Anísio Teixeira (INEP), pelo Instituto Brasileiro de Geografia e Estatística (IBGE) e pela Secretaria de Educação, Cultura e Esporte (SEDUCE) de Goiás.

$\mathrm{Na}$ segunda etapa, optamos pela observação participante das rotinas de um colégio da rede estadual de Goiás, seguida de uma entrevista semiestruturada com um dos gestores responsáveis pela Gerência de Ensino Especial da SEDUCE. Foram ouvidas também a diretora, a coordenadora pedagógica, a professora de apoio e a professora de recursos do estabelecimento de ensino selecionado para o levantamento de dados.

Entre os critérios definidos para a seleção dessa unidade destacamos, em primeiro lugar, a oferta do AEE e do Ensino Fundamental, Fases I e II (etapas que constituem um dos contornos de nosso objeto de estudo). A partir desse levantamento, o critério de delimitação foi a quantidade de alunos com NEEs matriculados nos estabelecimentos de ensino da localidade. Na seleção do espaço, priorizamos a escola que tivesse um número relevante $^{5}$ de estudantes com deficiências, TGD e/ou altas habilidades/superdotação, levando em consideração o recorte sugerido pela Política Nacional de Educação Especial na Perspectiva da Educação Inclusiva (BRASIL, 2008). Por fim, priorizamos o desempenho no IDEB das escolas nas Fases I e II do Ensino Fundamental, verificando também as médias obtidas nas últimas cinco edições da Prova Brasil (2005, 2007, 2009, 2011 e 2013). Tendo em vista o prestígio social vinculado ao índice nacional, examinamos os fatores envolvidos na participação do público-alvo da educação especial no exame em 
http://dx.doi.org/10.5902/1984686X39687

uma unidade escolar "bem avaliada". Entre as questões que fundamentaram nosso recorte estão: Como as "melhores escolas", do ponto de vista do desempenho nos testes padronizados, lidam com a questão da inclusão escolar dos alunos com NEEs? Existe articulação entre as políticas de inclusão e avaliação em larga escala no estabelecimento investigado? Se sim, como? Se não, por quê? Quais são os desafios e problemas vivenciados pelos alunos, professores e gestores nesse processo? As crianças com deficiências, TGD e altas habilidades/superdotação têm participado da Prova Brasil e de outras avaliações externas realizadas nessa unidade? O que podemos dizer em relação à sua participação e ao seu rendimento? O que pensam os profissionais entrevistados sobre o assunto?

Empenhamo-nos, desta forma, na investigação das consequências da lógica de mercado para a estruturação do discurso em defesa das diferenças e para a materialização das concepções de "justiça social" e "equidade" presentes em alguns documentos orientadores como a Declaração de Salamanca (UNESCO, 1994), a Declaração Mundial sobre Educação para Todos (UNESCO, 1990) e a Política Nacional de Educação Especial na Perspectiva da Educação Inclusiva (BRASIL, 2008). Analisamos, enfim, a interferência do neoliberalismo nas formas de organização do trabalho educativo e no acirramento das desigualdades no contexto escolar, tendo como delimitação o atendimento ao público-alvo da educação especial na perspectiva da educação inclusiva.

Será possível compatibilizar as formulações de base neotecnicista (SAVIANI, 2013), que têm os testes padronizados e as táticas de responsabilização como "carro chefe" (GATTI, 2013), com a proposta de educação especial na perspectiva inclusiva, fundamentada no respeito às diferenças e na temporalidade flexível dos processos de ensino-aprendizagem? Vejamos o que os dados coletados na investigação indicaram.

\section{Resultados e discussões}

Apresentaremos agora os dados coletados entre os meses de maio e setembro de 2015 em uma escola da rede estadual goiana. Os relatos fornecidos pela equipe responsável pela Gerência de Ensino Especial da SEDUCE no mesmo período também servem como um apoio importante.

Segundo informações disponibilizadas pela equipe gestora da Escola Helena Antipoff $^{6}, 34$ alunos apresentavam NEEs e frequentavam o AEE no contraturno, sendo 31 
http://dx.doi.org/10.5902/1984686X39687

do Ensino Fundamental (Fases I e II) e 3 da Educação de Jovens e Adultos (EJA). Lembramos que, de acordo com as diretrizes estaduais, além dos alunos com deficiências, TGD e altas habilidades/superdotação, a rede oferece AEE e professores de apoio aos estudantes com TDAH, dislexia, disgrafia, discalculia ${ }^{7}$ etc. A frequência às SRMs (Salas de Recursos Multifuncionais) é definida majoritariamente por laudos médicos e, eventualmente, por relatórios psicológicos e psicopedagógicos, o que demonstra a tendência histórica de individualização da deficiência e dos processos pedagógicos de não aprendizagem, bem como a baixa utilização do Plano de Atendimento Educacional Especializado (PAEE) na definição do público atendido pelas SRMs. Vejamos a tabela abaixo:

Tabela 1: Tipos de necessidades educacionais especiais atendidas pela escola Helena Antipoff

\begin{tabular}{c|c}
\hline $\begin{array}{c}\text { Tipos de necessidades educacionais } \\
\text { especiais }\end{array}$ & $\begin{array}{c}\text { Quantidade de alunos atendidos no AEE no } \\
\text { contraturno }\end{array}$ \\
\hline Deficiência Intelectual & 17 \\
\hline $\begin{array}{c}\text { Transtornos Globais de Desenvolvimento } \\
\text { (TGD) }\end{array}$ & 1 \\
\hline Transtorno desintegrativo da infância & 1 \\
\hline Deficiência múltipla & 2 \\
\hline Deficiência múltipla & 2 \\
\hline Deficiência auditiva & 1 \\
\hline Transtorno de Déficit de Atenção e \\
Hiperatividade (TDAH) & 6 \\
\hline Distúrbios de aprendizagem & 7 \\
\hline & TOTAL $=35$ alunos $^{8}$ \\
\hline
\end{tabular}

Fonte: Autoria dos pesquisadores.

Os alunos com NEEs atendidos na Escola Helena Antipoff apresentam um grau de comprometimento físico/cognitivo variado. Em média, são atendidos de 2 a 4 estudantes em cada turno do AEE. Eles são agrupados por nível de desenvolvimento e realizam as atividades de forma conjunta. No que se refere especificamente, à avaliação da aprendizagem desses estudantes, os professores mencionam o uso de portfólios, de atividades adaptadas (tanto nas salas regulares, pelos professores de apoio à inclusão, quanto na sala de AEE, pela professora de recursos) e do Formulário de Avaliação para a Diversidade disponibilizado pela Gerência de Ensino Especial da SEDUCE.

Considerando o recorte de nossa pesquisa, salientamos que a escola alcançou notas satisfatórias no IDEB, vinculada a um aumento crescente nas médias no período que vai de 2005 a 2013. Nessa perspectiva, ultrapassou as metas previstas para o estado de Goiás, superando, inclusive, as projeções para o ano de 2021. 
http://dx.doi.org/10.5902/1984686X39687

Tabela 2: Dados referentes aos anos iniciais do Ensino Fundamental da Escola Helena Antipoff - Metas e desempenho do IDEB.

\begin{tabular}{ccc}
\hline \multicolumn{2}{c}{ IDEB } \\
\hline Ano & Meta & Desempenho \\
\hline $2005^{9}$ & --- & 5,0 \\
2007 & 5,0 & 3,7 \\
2009 & 5,3 & 5,7 \\
2011 & 5,7 & 6,1 \\
2013 & 6,0 & 7,3 \\
\hline
\end{tabular}

Fonte: http://idebescola.inep.gov.br/ideb/escola/dadosEscola/52035301. Acesso em 04 set. 2015.

De acordo com os depoimentos coletados em campo, entre as possíveis explicações para o aumento do IDEB da Escola Helena Antipoff nas Fases I e II do Ensino Fundamental entre 2005 e 2013, está o esforço integrado da equipe no "treino" das habilidades/competências exigidas pela Prova Brasil, com foco nas disciplinas de Língua Portuguesa e Matemática. Gradualmente, a Prova Brasil foi adquirindo centralidade como estratégia de controle dos resultados, mobilizando grandes esforços da equipe a cada nova edição. De acordo com as falas dos professores e da gestora da unidade, o comprometimento coletivo com a elevação da proficiência e das taxas de aprovação decorre, em grande parte, das exigências do Estado em relação ao desempenho geral das escolas nos testes padronizados.

No período em que estivemos em campo, a Escola Helena Antipoff iniciou um intenso processo de preparação para a Prova Brasil de 2015. Entre as ações planejadas para os meses de setembro e outubro, estava a realização de "aulões" (termo utilizado pela diretora e pelos docentes) de reforço aos sábados, nos períodos matutino e vespertino, organizados por professores regentes e estagiários.

\footnotetext{
Nós já temos aí o material preparado e elaborado pela escola. Nós acessamos pela internet, pegamos os cadernos educacionais, "xerocamos". Esse é o material de apoio do professor. Então, estamos nesse esquema de força tarefa. Durante o ano todo nós temos esse foco. Na verdade, todos os anos, porque 0 ano que antecede é uma preparação para o ano seguinte. [...] Acredito que nós precisamos fazer de tudo para manter, no mínimo, a nota da escola no IDEB (Diretora da Escola Helena Antipoff).
}

Em sua entrevista, a diretora ressaltou a intensa pressão sofrida pela instituição no período que antecede a Prova Brasil, destacando a importância de uma boa estratégia de ação e de uma boa preparação para o teste. Segundo a servidora, em tempos de avaliação externa, é preciso organizar uma "força tarefa" que integre todos os estudantes e funcionários da escola. 
http://dx.doi.org/10.5902/1984686X39687

Quanto à participação dos alunos das Fases I e II do Ensino Fundamental da Escola Helena Antipoff na Prova Brasil de 2013, os dados do INEP indicaram o seguinte cenário:

Tabela 3 - Participação dos estudantes na Prova Brasil de 2013 - Escola Helena Antipoff

\begin{tabular}{|c|c|c|c|c|}
\hline \multirow[b]{2}{*}{ Alunos } & \multicolumn{2}{|c|}{ Anos Iniciais (4ª̊série/5ㅇaㅇ) } & \multicolumn{2}{|c|}{ Anos Finais ( $8^{a}$ série/9ao) } \\
\hline & Matriculados & Participantes & Matriculados & Participantes \\
\hline Total & 53 & 44 & 60 & 60 \\
\hline Idade média ${ }^{10}$ & 10,4 & 10,4 & 14,6 & 14,6 \\
\hline $\begin{array}{l}\text { Percentual de } \\
\text { incluídos }^{11}\end{array}$ & $1,9 \%$ & $0,0 \%$ & $1,7 \%$ & $1,7 \%$ \\
\hline $\begin{array}{c}\text { Percentual } \\
\text { total de não } \\
\text { aprovados }\end{array}$ & $3,8 \%$ & $0,0 \%$ & $5,0 \%$ & $3,6 \%$ \\
\hline
\end{tabular}

Fonte: http://idebescola.inep.gov.br/ideb/escola/dadosEscola/52035301. Acesso em: 04 set. 2015.

Tomando como base os alunos público-alvo da educação especial inclusiva, vemos que o único "aluno incluído" do 5 ano não participou da edição 2013 da Prova Brasil. 0 mesmo não ocorreu no $9^{\circ}$ ano, já que o único "aluno incluído" realizou o exame. Segundo informações fornecidas pela professora de recursos, o estudante mencionado ${ }^{12}$ contou com a ajuda da professora de apoio no momento da aplicação, registrando um bom desempenho. Infelizmente, nos limites de nossa pesquisa, não foi possível obter informações mais precisas sobre suas notas. No que se refere ao $5^{\circ}$ ano, o único aluno com NEEs matriculado ${ }^{13}$ não compareceu no dia da aplicação.

Os dados coletados nas entrevistas revelaram que a participação de alunos com NEEs (incluindo TDAH e/ou dificuldades de aprendizagem) nas últimas edições da Prova Brasil está sujeita a critérios definidos internamente, suportando flexibilizações, que variam de acordo com o nível de desenvolvimento da criança e/ou jovem e da sua apropriação dos conteúdos exigidos pelo exame. As falas da diretora do estabelecimento atestam as dúvidas dos professores em relação à avaliação desses estudantes e à sua participação nos testes padronizados:

Nós discutimos nas nossas reuniões [...] sobre essa angústia, do aluno do AEE fazer parte das avaliações externas à escola. É um direito dele, porém, todos nós sabemos que quando ele participa, entre aspas, ele acaba por baixar o rendimento da escola. Por quê? Porque, ali ele não vai ter uma nota muito grande e, se ele fizer sozinho, ele não consegue. Muitos não têm a competência para fazerem sozinhos, precisam da professora de apoio. E se faz, a gente fica se questionando: até quando, até quanto, quantitativamente e qualitativamente, essa professora apoia esse aluno quando ele está fazendo a prova? Então, essa é a nossa pergunta (Diretora da Escola Helena Antipoff). 
http://dx.doi.org/10.5902/1984686X39687

A despeito da ampliação das discussões no campo das políticas inclusivas, vemos que argumentos deterministas têm sido utilizados para legitimar a exclusão de alunos com NEEs dos exames nacionais, sobretudo quando tratamos de estudantes com deficiência intelectual e TGD. Acredita-se, de fato, que eles não sejam capazes de concluir o exame ou de alcançar médias satisfatórias em Língua Portuguesa e Matemática. Os "déficits" de aprendizagem, os "desvios" comportamentais e as limitações de ordem cognitiva/comunicacional emergem, pois, como categorias centrais na caracterização desse alunado, o que indica a permanência de uma concepção normalizadora de educação, segundo a qual a deficiência é, irremediavelmente, sinônimo de incapacidade.

Embora demonstre estar ciente das diretrizes que fundamentam as práticas inclusivas, a diretora expressa em seu depoimento, de forma contundente, as contradições envolvidas na materialização do discurso em defesa das diferenças no contexto escolar. Ao mesmo tempo em que deseja garantir a participação dos alunos com NEEs nas avaliações externas, é pressionada a elevar a nota da escola no IDEB. Nessa perspectiva, segundo ela, a exclusão de alunos cujo nível de desenvolvimento e aprendizagem se encontre abaixo do esperado é justificável, ainda que não seja o ideal.

\footnotetext{
Se ele (o aluno) não participa a gente exclui. Se ele participa sem aquele "apoio" do professor, na hora da realização da prova, ele leva o nível lá embaixo. Mas de acordo com nosso intuito aqui, ele participa sim. Às vezes ele não conta como aluno da inclusão. Ele entra nos dados como aluno da escola, como se ele não fosse da inclusão, e isso é complicado. É isso que faz descer muito a nota. Alguns alunos nós acreditamos que não devam participar devido ao grau de comprometimento. Porque acabam por prejudicar. Então, nós tivemos uma avaliação diagnóstica agora. $O$ aluno Tales, autista, obteve a maior nota de proficiência. Então a gente se pergunta, até quando? Ótimo, se ele for proficiente, mas é real? (Diretora da Escola Helena Antipoff).
}

As falas da professora de recursos da Escola Helena Antipoff retomam elementos já mencionados por sua colega de trabalho, discorrendo sobre atuação dos profissionais de apoio à inclusão e sobre o embate entre as políticas inclusivas e a proposta de avaliação em larga escala disseminada pelo MEC e pelo INEP:

Acho que inclusão é isso, o aluno participar do todo, inclusive das avaliações externas. Eu acho que é positivo. Não só para eles mas para os próprios colegas. [...] Eu achei até interessante porque um professor de apoio pôde auxiliar um aluno do $5^{\circ}$ ano. E o estudante Tales tirou nota alta (na última avaliação diagnóstica realizada na escola) ${ }^{14}$. Então, nós questionamos porque ele tem laudo e tal. Mas a professora foi orientando e ele desenvolveu bem. Aliás, até melhor que os outros. Eles participam sim, [...] apesar de que é opcional. A tutora falou que o aluno que tem muita dificuldade e, vai ter agora a prova, esse é ano de IDEB. Os que tiverem muitas dificuldades podem ficar como ausentes. Isso no caso de uma 
http://dx.doi.org/10.5902/1984686X39687

dificuldade muito grande. Então a gente não sabe se é real. Porque a inclusão fala uma coisa e, às vezes, o sistema pede outra. Eu soube também que os profissionais de apoio podem ajudar esses alunos. Bem, quem sou eu para questionar o que o professor fez, qual a porcentagem de ajuda. Eles já tem a maturidade para saber até onde podem ir, o que podem fazer. Porque também o aluno especial, com laudo, com dificuldade, com a nota máxima (da escola no IDEB), daí fica quase impossível (Professora de recursos da Escola Helena Antipoff).

Voltando à questão das atividades de preparação para a Prova Brasil de 2015, a professora de recursos ressalta:

\begin{abstract}
Porque na Prova Brasil os alunos que não têm o costume de ler sofrem demais. Tem aluno que eu sei que sabe ler, mas na prova eles colocam um texto enorme. Você tem que estimular os alunos a lerem. Se não, eles deixam aquilo ali pela metade. Aí falam: "não pode ajudar". Mas não tem jeito de ficar sem ajudar! [...] No $5^{\circ}$ ano nós temos um aluno que tem muitas dificuldades $^{15}$ [...]. Eu e a professora Carmen ${ }^{16}$ estamos fazendo um diagnóstico. E no 9o ano são dois alunos, que talvez fiquem de fora (Professora de recursos da Escola Helena Antipoff).
\end{abstract}

Em suas falas, as entrevistadas defendem a participação de todos os alunos com NEEs nos testes padronizados. Por outro lado, também aprovam o afastamento daqueles cujos graus de comprometimento possam interferir no alcance das metas sugeridas para a escola (segundo os critérios definidos por professores e gestores). As profissionais, de fato, pareciam encontrar dificuldades para cumprir as exigências trazidas pelas políticas educacionais implementadas no âmbito da antiga Secretaria de Educação Continuada, Alfabetização, Diversidade e Inclusão (SECADI) ${ }^{17}$ e do INEP, concluindo que "a inclusão fala uma coisa e, às vezes, o sistema pede outra" - como foi dito pela professora de recursos da Escola Helena Antipoff.

Como vemos, a questão da participação dos alunos com deficiências e outros problemas nas avaliações externas torna latentes os conflitos, preconceitos e questionamentos que já existiam mas que adquirem, no contexto neotecnicista, uma nova conformação. Reportando-se às determinações trazidas pelo SAEB, a gestora responsável pela Gerência de Ensino Especial da SEDUCE discute a interferência dos testes padronizados no fortalecimento dos processos de exclusão de estudantes com NEEs nas escolas da rede estadual:

Então, preocupados, por exemplo, com os índices e resultados, muitas vezes eles (os professores) excluem os alunos com deficiência durante 0 processo, porque entendem assim: ele vai abaixar a minha nota. Então, às vezes, ele é excluído. Às vezes ele fica lá aguardando o término da prova. Isso eu não vou generalizar, não são todos, mas tem lugares em que isso acontece. [...] ainda há uma dificuldade considerável na mediação dos conteúdos. Como é que você cobra de um aluno o que você não ensinou? 
http://dx.doi.org/10.5902/1984686X39687

O que fazer com esse aluno? O aluno está lá, não está participando da avaliação ou está, mas não consegue responder. Essas discussões são sempre colocadas mesmo. O que é bom! Quer dizer que é uma coisa que está incomodando, para a qual nós precisamos encontrar uma saída, uma solução. Mas embora haja uma preocupação da rede e dos professores regentes com o assunto, a solução nem sempre é a mais acertada. Acaba sendo aquela de, em último caso, excluir o aluno do processo (Gestora responsável pela Gerência de Ensino Especial da SEDUCE).

Quando questionada sobre a adequabilidade da Prova Brasil como instrumento de aferição do desempenho escolar de alunos com NEEs, a diretora da Escola Helena Antipoff foi taxativa na crítica aos procedimentos adotados pelo MEC e pelo INEP. Segundo ela, os testes padronizados não contemplam, de forma alguma, as particularidades que caracterizam os estudantes com deficiências, TGD e outros distúrbios de aprendizagem ${ }^{18}$ :

Então, relacionando a Prova Brasil com essa parte inclusiva, deixa muito a desejar. Porque aqui a gente trabalha com a adaptação dos conteúdos. Então a prova é diferenciada. As atividades deles (dos alunos) são diferenciadas. Mas a Prova Brasil não. Então ela não contempla a inclusão. As avaliações diagnósticas não contemplam a inclusão. Deveria ter uma avaliação diferenciada. Da mesma forma que é para o aluno $A$, ela vai para o aluno B. O aluno da inclusão realiza avaliação com o professor de apoio. E se o professor só lê a prova da forma como está ali (porque ele não pode sugerir resposta para o aluno, não pode induzi-lo à resposta), o aluno não consegue compreender. Aí os meninos ficam assim: "Eu não entendi. Do que a senhora está falando? Eu não entendi, explica de novo!". Por quê? Porque não está adaptado. [...] Então as avaliações não estão adequadas à realidade da inclusão, infelizmente. Mais uma vez o aluno é excluído, não só pela sociedade, mas pelo processo (Diretora da Escola Helen Antipoff).

Como vimos no fragmento acima, na visão da gestora, há uma incompatibilidade entre os princípios defendidos pelas políticas inclusivas e as bases teórico-metodológicas das avaliações em larga escala, com foco na Prova Brasil. A devolutiva da avaliação por meio de notas sugere a formulação de rígidas escalas de classificação por desempenho, desconsiderando a diversidade de ritmos de aprendizagem e as habilidades desenvolvidas pelos educandos ao longo de seu período de escolarização (CARDOSO e MAGALHÃES, 2013; FREITAS, 2004; SOUSA, 2018; REBELO e KASSAR, 2018).

Seguindo essa mesma linha de raciocínio, a diretora vincula os testes padronizados ao acirramento dos processos de exclusão de alunos com NEEs, explicitando os inúmeros problemas enfrentados pelos docentes e discentes no momento da aplicação. A extensão dos enunciados, a quantidade de questões e o tempo reduzido para realização do teste são algumas das barreiras que, segundo ela, contribuem para o "fracasso" desses estudantes na Prova Brasil e em outras avaliações externas. 
Tais aspectos nos levam a crer, portanto, que a proposta de avaliação em larga escala se sobrepõe às exigências trazidas pela Política Nacional de Educação Especial na Perspectiva da Educação Inclusiva (BRASIL, 2008) e outros documentos orientadores - o que indica um retrocesso na superação da exclusão escolar de educandos com deficiências e TGD. Entretanto, é preciso que nos questionemos quanto à relevância dessa participação. Os dados levantados em campo nos levam a crer que o bom desempenho das escolas no IDEB está atrelado as táticas de treinamento para o teste que são, inclusive, estimuladas pela SEDUCE, tendo como horizonte o alcance das metas estipuladas pelo MEC.

Os aspectos observados em campo, atrelados às falas coletadas anunciam a presença de duas lógicas distintas nas escolas analisadas. De um lado temos as políticas inclusivas, fundamentadas no respeito à diversidade e na plena participação dos alunos com NEEs na rotina das salas regulares (BRASIL, 2008). Do outro, temos as avaliações em larga escala, que acirram a competição entre escolas e redes de ensino, contribuindo para a padronização dos desempenhos e para a legitimação das várias formas de exclusão no contexto escolar (FREITAS, 2004).

Segundo as políticas inclusivas, as unidades de ensino devem atender à diversidade, oferecendo recursos alternativos e instrumentos de acessibilidade adequados para cada caso (BRASIL, 2003). Contudo, também devem trabalhar para que todos os estudantes alcancem resultados equivalentes em um mesmo período de tempo, dominando competências e saberes que serão aferidos em testes de rendimento periódicos. Nesse sentido, erroneamente, a ideia de equidade se vincula ao acesso igualitário a determinados conteúdos que compõem as matrizes de referência das avaliações em larga escala no Brasil (FREITAS, 2013).

As escolas incorporam variações nos processos de ensino/aprendizagem no campo da educação especial na perspectiva inclusiva (GARCIA, 2013) mas, simultaneamente, são pressionadas a elevar os resultados no IDEB, aderindo à uma lógica fundamentada na padronização dos desempenhos, na responsabilização e na competitividade (FREITAS, 2012).

Isso nos leva a refletir sobre o preocupante "engessamento" das práticas e rotinas escolares (HORTA NETO, 2013), na medida em que professores não têm liberdade para propor temas e novas abordagens, tendo que repassar apenas os conteúdos exigidos pelo INEP e pelo MEC. É o que Bonamino \& Sousa (2012) chamam de "ensinar para o 
http://dx.doi.org/10.5902/1984686X39687

teste": quando os educadores concentram seus esforços nos tópicos que serão avaliados, desconsiderando outros aspectos importantes do currículo. Segundo Sordi $(2012$, p. 1) ao se optar "por modelos regulatórios concebidos a partir dos interesses de mercado, as escolas, ainda que bem posicionadas no ranqueamento a que são expostas, observam seus objetos pedagógicos reduzidos aos limites contidos e explorados nos exames de desempenho".

$\mathrm{Na}$ escola pesquisada, estudantes com NEEs deixaram de realizar a Prova Brasil 2013 em virtude de faltas não justificadas. De acordo com Horta Neto (2013, p. 157), a questão da ausência dos alunos nos exames vem sendo discutida pela literatura internacional, constituindo um grave problema ligado à precisão da medida. Aparece também como uma das "várias tentativas de enganar o sistema com o objetivo de obter scores mais altos nos testes", algo comum quando falamos em avaliações de alto impacto (FREITAS, 2011; RAVITCH, 2011) e/ou avaliações da terceira geração (BONAMINO e SOUSA, 2012).

Assim, de acordo com Freitas (2013, p. 89), "deixa-se de fora da sala de aula os alunos com dificuldades de aprendizagem para com isso não prejudicar a medida de desempenho da escola". De forma similar, estudantes com baixo aproveitamento escolar são estimulados a "se ausentarem no dia da aplicação da prova". Aqui nos aproximamos do conceito de "crianças da margem", detalhado por Cardoso e Magalhães (2012), que são aquelas que, em virtude de suas limitações de ordem física/cognitiva, são excluídas das avaliações externas ou não têm suas notas computadas pelos sistemas de ensino.

A coexistência de instrumentos distintos de avaliação de desempenho demanda estratégias díspares das equipes pedagógicas. De acordo com a Proposta de Avaliação para a Diversidade, utilizada pela Gerência de Ensino Especial da SEDUCE, os professores devem levar em consideração elementos que não podem ser efetivamente mensurados, como os conceitos espontâneos (vinculados às experiências e conhecimentos que o aluno já possui), o nível de desenvolvimento potencial (concebido a partir do contato de crianças/jovens com seus pares e do intercâmbio com parceiros mais experientes), a evolução das condições socioafetivas, entre outros aspectos.

A preparação para as avaliações em larga escala, por sua vez, exige um outro tipo de posicionamento por parte dos docentes e gestores, atrelado ao treinamento para 0 teste e ao domínio de conteúdo, que são dispostos em matrizes curriculares de 
referência. Para que resultados positivos sejam alcançados pelas escolas no IDEB, é imprescindível que todos os alunos obtenham notas satisfatórias.

Os dados coletados na pesquisa indicaram uma tensão entre a proposta de educação inclusiva e a lógica neotecnicista que sustenta as avaliações em larga escala no Brasil. O fato é que as escolas são convocadas a garantir a inclusão dos alunos com NEEs nas salas regulares, atentando para as especificidades envolvidas em seu processo de aprendizagem e desenvolvimento - o que exige a utilização de ferramentas pedagógicas alternativas, tecnologias assistivas, recursos de apoio e estratégias de acessibilidade. Entretanto, temos também a pressão por resultados, materializados em um índice geral de desempenho que não considera as condições heterogêneas nas quais o trabalho educativo se desenvolve (GATTI, 2013).

Como discutimos anteriormente, o ambiente escolar emerge, pois, como espaço de tensão entre diferentes projetos de formação humana. De um lado temos a diversidade como o núcleo de referência, em torno do qual deverão ser planejados os recursos didáticos, os métodos de ensino, o trabalho educativo e a avaliação da aprendizagem. Do outro, temos o enfoque na proficiência dos alunos nos testes padronizados, numa perspectiva pragmática, meritocrática e classificatória. Tal constatação evidencia a centralidade do par dialético inclusão/exclusão (MICHELS, 2006; FREITAS et al., 2004) como ferramenta mais adequada na interpretação das contradições cristalizadas no contexto escolar - que emerge como campo de disputa entre diferentes projetos de formação humana (SAVIANI, 2013).

\section{Considerações finais}

Acreditamos que a pesquisa realizada traz uma contribuição relevante ao estudo do tema, haja vista a gradual elevação no número de matrículas de estudantes com NEEs na rede pública de ensino. De acordo com a legislação específica, esses estudantes devem participar dos testes padronizados, desenvolvidos nos âmbitos federal, estadual e municipal. De fato, há uma demanda por orientações mais precisas que deem conta dos impasses enfrentados pelas escolas na compatibilização entre políticas educacionais inclusivas e as diretrizes referentes às avaliações externas - ambas veiculadas pelo MEC a partir da década de 1990.

A partir do referencial bibliográfico adotado e do material coletado em campo, pudemos vislumbrar o confronto entre duas lógicas distintas, o que indica o embate mais 
amplo entre as diretrizes da extinta SECADI e as orientações presentes no Plano de Metas Compromisso Todos pela Educação, divulgado pelo MEC em 2007. No âmbito estadual, atestamos o conflito entre o trabalho encabeçado pela Gerência de Ensino Especial da SEDUCE e as metas registradas no Pacto pela Educação: um futuro melhor exige mudanças (GOIÁS, 2011) - implementado no terceiro mandato do governador Marconi Perillo, do Partido da Social Democracia Brasileira (PSDB). Outro desdobramento deste problema é a incompatibilidade entre a Proposta de Avaliação para a Diversidade da Gerência de Ensino Especial e a abordagem neotecnicista (FREITAS, 2011) sugerida pelas avaliações em larga escala, sobretudo pela Prova Brasil.

Tal discrepância, a nosso ver, indica a prevalência de uma política educacional fragmentada, que lança mão de uma série de programas, projetos e ações desarticulados(as) entre si (GARCIA, 2013). Tal oposição se torna latente quando confrontamos a legislação que regulamenta a educação especial inclusiva e os documentos que sustentam as táticas de monitoramento do ensino via testes padronizados. Daí a necessidade de uma discussão sobre os níveis de coesão desejáveis na relação entre a União e os entes federados, bem como na articulação entre departamentos, gerências e coordenadorias que compõem as Secretarias/Subsecretarias de Educação distribuídas nas várias localidades do país.

Os professores, coordenadores e gestores entrevistados em nossa pesquisa demonstraram um bom conhecimento em relação aos princípios e diretrizes que orientam as políticas de inclusão. Todavia, no contexto escolar, as normas adquirem uma nova conformação, considerando os obstáculos e impedimentos trazidos pela prática. Nesse espaço de enfrentamento, evidenciamos a centralidade do par dialético inclusão/exclusão. Trata-se, como pudemos demonstrar, de uma categoria central na interpretação das contradições decorrentes da presença do público-alvo da educação especial na perspectiva inclusiva nas salas regulares e no estudo de sua participação e/ou exclusão das avaliações externas.

Nossas análises certificaram que a abordagem neotecnicista interfere nas formas de organização do trabalho educativo e na definição dos conteúdos curriculares que serão ministrados pelos professores, em conformidade com as metas definidas pelo MEC, pelas agências multilaterais e pelo próprio governo do estado de Goiás. Na medida que os estabelecimentos de ensino são pressionados a apresentar resultados satisfatórios nos testes padronizados, há uma consequente demanda pelo estreitamento da atuação 
docente, o que envolve um planejamento voltado para os tópicos solicitados pelos exames nacionais vinculados ao SAEB.

As chances de progressão nos estudos, o rompimento em relação à lógica neoliberal e uma educação comprometida com os processos de humanização (SAVIANI, 2013; MARSIGLIA, 2012) constituem pontos centrais nesse embate - o que sugere a superação das várias formas de exclusão e marginalização a que foram sujeitas, historicamente, as pessoas consideradas com padrões atípicos de desenvolvimento e aprendizagem.

Reiteramos que a definição de um "padrão de qualidade" desejável para a educação não constitui um problema. Muito pelo contrário. Em sua origem, o termo nos remete à ideia de aperfeiçoamento que, se encaminhada de forma coerente, pode produzir melhorias e transformações significativas no âmbito social, político, econômico etc. O que criticamos aqui são os critérios utilizados em sua delimitação, o que envolve aspectos políticos e ideológicos, nivelados com o arranjo neoliberal e com os interesses do capital (SAVIANI, 2011; FREITAS, 2011).

A agenda dos reformadores empresariais (FREITAS, 2012) e das agências multilaterais se revela, pois, incompatível com uma proposta de educação emancipadora que favoreça o processo de humanização, o reconhecimento das diferenças e a formação de sujeitos críticos (SAVIANI, 2013). Sendo assim, é preciso que ampliemos as discussões sobre estratégias contra-regulatórias de avaliação (SORDI, 2012; FREITAS et al., 2009), confrontando de forma direta os mecanismos de exclusão de alunos com NEEs dentro e fora da escola.

\section{Referências}

BONAMINO, Alícia Maria Catalano de. Tempos de avaliação educacional: o SAEB, seus agentes, referências e tendências. Rio de Janeiro: Quartet, 2002.

BONAMINO, Alícia Maria Catalano de; SOUSA, Sandra Maria Zákia Lian. Três gerações de avaliação da educação básica no Brasil: interfaces com o currículo da/na escola. Educação e Pesquisa, São Paulo, v. 38, n. 2, p. 373-388, abr./jun. 2012.

BRASIL. Ministério de Educação. Lei no 9.394 de 20 de dezembro de 1996. Estabelece as Diretrizes e Bases da Educação Nacional. Brasília: MEC, 1996.

BRASIL. Ministério da Educação. Estratégias para a educação de alunos com necessidades educacionais especiais. Brasília: MEC/SEE, 2003. 
http://dx.doi.org/10.5902/1984686X39687

BRASIL. O Plano de Desenvolvimento da Educação - PDE: razões, princípios e programas. Brasília: MEC, 2007.

BRASIL. INEP. Portaria no 87, de 07 de maio de 2009. Diário Oficial da União, Brasília, Seção 1, p. 48, n. 86, 8 maio. 2009.

BRASIL. Decreto 7.611 de novembro de 2011. Dispõe sobre o Atendimento Educacional Especializado e dá outras providências. Brasília: MEC, 2011. Disponível em:

http://www.planalto.gov.br/ccivil_03/_ato2011-2014/2011/decreto/d7611.htm. Acesso em: 06 abr. 2015.

CARDOSO, Ana Paula Lima Barbosa; MAGALHÃES, Rita de Cássia Barbosa Paiva. Educação especial e avaliações em larga escala no município de Sobral (CE). Revista de Educação Especial, Santa Maria, v. 25, n. 44, p. 449-464, set./dez. 2012.

FREITAS, Dirce Nei Teixeira de. Avaliação da educação básica no Brasil: dimensão normativa, pedagógica e educativa. Campinas: Autores Associados, 2007.

FREITAS, Dirce Nei Teixeira de. Avaliação da educação básica no Brasil: características e pressupostos. In: BAUER, Adriana; GATTI, Bernadete Angelina; TAVARES, Marialva Rossi (Orgs). Vinte e cinco anos de avaliação de sistemas educacionais no Brasil. Florianópolis: Insular, 2013.

FREITAS, Luíz Carlos de et al. Dialética da inclusão e da exclusão: por uma qualidade negociada e emancipadora nas escolas. In: GERALDI, Corinta Maria Grisolia; RIOLFI, Claudia Rosa; GARCIA; Maria de Fátima (Orgs.) Escola viva: elementos para a construção de uma educação de qualidade social. Campinas: Mercado das Letras, 2004.

FREITAS, Luiz Carlos de et al. Avaliação educacional: caminhando pela contramão. Petrópolis: Vozes, 2009.

FREITAS, Luiz Carlos de. Responsabilização, meritocracia e privatização: conseguiremos escapar ao neotecnicismo? Texto apresentado no III Seminário de Educação Brasileira promovido pelo CEDES no Simpósio do PNE - Diretrizes para avaliação e regulação da educação nacional, em fevereiro de 2011. Disponível em: www.cedes.unicamp.br/seminario3 /luiz_freitas.pdf. Acesso em: 15 jul. 2015.

FREITAS, Luiz Carlos de. Os reformadores empresariais da educação: da desmoralização do magistério à destruição do sistema público de educação. Educação \& Sociedade, v. 33, p. 379-404, 2012.

GARCIA, Rosalba Maria Cardoso. Política de educação especial na perspectiva inclusiva e a formação docente no Brasil. Revista Brasileira de Educação, v. 18, n. 52, p. 101 113, jan./mar. 2013.

GATTI, Bernadete Angelina. Possibilidades e fundamentos de avaliações em larga escala: primórdios e perspectivas contemporâneas. In: BAUER, Adriana; GATTI, Bernadete Angelina; TAVARES, Marialva Rossi (Orgs). Vinte e cinco anos de avaliação de sistemas educacionais no Brasil. Florianópolis: Insular, 2013. 
http://dx.doi.org/10.5902/1984686X39687

GOIÁS. Resolução CEE no 07 de 15 de dezembro de 2006. Goiânia: Conselho Estadual de Educação, 2006.

GOIÁS. Diretrizes Operacionais da Rede Pública Estadual de Ensino de Goiás 20112012. Goiânia: Secretaria Estadual de Educação, 2010.

GOIÁS. Secretaria de Estado da Educação. Pacto pela Educação: um futuro melhor exige mudanças. Goiânia: SEDUC, 2011. Disponível em:

http://www.seduc.go.gov.br/especiais/pactopelaeducacao/docs/Microsoft20PowerPoint\%2 $0-$

\%20.\%20\%20Lan\%C3\%A7amento\%20do\%20Pacto\%20Pela\%20EducaC3\%A7\%C3\%A3 o\%20-\%20Reforma\%20Educacional\%20Goiana.pdf. Acesso: 20 ago. 2017.

HORTA NETO, João Luiz. IDEB: limitações e usos do indicador. In: BAUER, Adriana; GATTI, Bernadete Angelina; TAVARES, Marialva Rossi (Orgs). Vinte e cinco anos de avaliação de sistemas educacionais no Brasil. Florianópolis: Insular, 2013.

MARSIGLIA, Ana Carolina Galvão. O tema da diversidade na perspectiva da pedagogia histórico-crítica. In: MARSIGLIA, Ana Carolina Galvão; BATISTA, Eraldo Leme (Orgs.).

Pedagogia histórico-crítica: desafios e perspectivas para uma educação

transformadora. Campinas: Autores Associados, 2012.

MENDES, Eniceia Gonçalves; D’AFFONSECA, Sabrina Mazo. Avaliação dos estudantes público-alvo da educação especial: perspectiva dos professores especializados. Revista Educação Especial, v. 31, n. 63, p. 923-937, out./dez. 2018.

MICHELS, Maria Helena. Gestão, formação docente e inclusão: eixos da reforma educacional brasileira que atribuem contornos à organização escolar. Revista Brasileira de Educação, Campinas, v. 11, n. 33, p. 406-423, set./dez. 2006.

RAVITCH, Diane. Vida e morte do grande sistema escolar americano: como os testes padronizados e o modelo de mercado ameaçam a educação. Porto Alegre: Editora Sulina, 2011.

REBELO, Andressa Santos; KASSAR, Mônica de Carvalho Magalhães. Avaliação em larga escala e educação inclusiva: os lugares do aluno da Educação Especial. Revista Educação Especial, v. 31, n. 63, p. 907-922, out./dez. 2018.

SAVIANI, Dermeval. História das ideias pedagógicas no Brasil. Campinas: Autores Associados, 2011.

SAVIANI, Dermeval. Pedagogia histórico-crítica: primeiras aproximações. Campinas: Autores Associados, 2013.

SILVA, Régis Henrique dos Reis; SILVA, Ribamar Nogueira da; MACHADO, Robson. Golpe de 2016 e a educação no Brasil: implicações nas políticas de educação especial na perspectiva da educação inclusiva. In: MAZZA, Débora; SPIGOLON, Nima Imaculada; FERREIRA, Lilian Zanvettor (Orgs.). 1937, 1964 e 2016: Brasil, tradição de golpes. [no prelo]. 
http://dx.doi.org/10.5902/1984686X39687

SORDI, Mara Regina Lemes de. Processos de responsabilização alternativos: a luta por concepções de qualidade na/da escola pública. In: ENDIPE - Encontro Nacional de Didática e Práticas de Ensino, XVI, 2012, Campinas. Trabalhos. [S. I.]: FE - Unicamp, 2012, p. 1-11. Disponível em:

http://www.infoteca.inf.br/endipe/smarty/template\%/arquivos_template/upload_arquivos /acervo/ docs/1701b.pdf. Acesso em: 02 jan. 2018.

SOUSA, Sandra Maria Zákia Lian. Avaliação em larga escala da educação básica e inclusão escolar: questões polarizadoras. Revista Educação Especial, v. 31, n. 63, p. 863-877, out./dez. 2018.

UNESCO. Declaração de Salamanca. Espanha, 1994. Disponível em: http://portal.mec.gov.br/ seesp/arquivos/pdf/salamanca.pdf. Acesso em: 02 jul. 2017.

UNESCO. Declaração Mundial sobre Educação para Todos. Conferência de Jomtien, 1990. Disponível em: http://www.direitoshumanos.usp.br/index.php/Direito-aEduca\%C3\%A7 \%C3\%A3\%/declaracao-mundial-sobre-educacao-para-todos.html. Acesso em 16 abr. 2017.

\section{Notas finais}

${ }^{1}$ Utilizaremos neste trabalho a definição público-alvo da educação especial citada na Política Nacional de Educação Especial na Perspectiva da Educação Inclusiva (BRASIL, 2008), no Parecer CNE/CEB n 13 de 03 de junho de 2009, no Decreto 7.611 de 17 de novembro de 2011 e na LDBEN (BRASIL, 1996), com redação alterada pela Lei 12.796 de 04 de abril de 2013.

${ }^{2}$ Tal delimitação referente ao público-alvo da educação especial encontra-se expressa na Política Nacional de Educação Especial na Perspectiva da Educação Inclusiva (BRASIL, 2008). Contudo, observando as particularidades da rede estadual goiana agregamos, em nossa análise, dados referentes aos estudantes com Transtorno de Déficit de Atenção e Hiperatividade (TDAH), dislexia e demais dificuldades de aprendizagem, que recebem atendimento especializado nas Salas de Recursos Multifuncionais (SRMs) e auxílio de profissionais de apoio à inclusão.

${ }^{3}$ O SAEB era originalmente composto por duas avaliações externas em larga escala: a ANEB (Avaliação Nacional da Educação Básica) e a ANRESC. Em 2013, foi incorporada ao sistema, pela Portaria Ministerial no 482 de 07 de junho, a Avaliação Nacional de Alfabetização (ANA), com o objetivo de aferir os níveis de alfabetização e letramento dos estudantes em Língua Portuguesa (leitura/escrita) e Matemática.

${ }^{4}$ Por principais periódicos entende-se aqueles melhor avaliados pela Coordenação de Aperfeiçoamento de Pessoal de Nível Superior (CAPES).

5 Considerando as estatísticas referentes às matrículas de alunos com NEEs nas escolas goianas divulgadas pelo MEC e pelo INEP nos anos de 2014 e 2015.

6 Tanto o nome da escola como dos membros da comunidade escolar são fictícios, para preservar suas identidades.

${ }^{7}$ Que no Relatório Nominal de Alunos com Necessidade Especial emitido pela SEDUCE são apresentados como distúrbios de aprendizagem.

${ }^{8}$ Lembramos que o somatório engloba os 34 alunos com NEEs matriculados na Escola Helena Antipoff e 1 estudante, proveniente de outra escola da rede estadual, que realiza o AEE na SRM do estabelecimento.

${ }^{9}$ Ausência de metas tendo em vista tratar-se do primeiro ano de aplicação da Prova Brasil no país.

${ }^{10}$ Os valores relacionados à idade média e percentual de "incluídos" foram apresentados a partir dos dados coletados apenas no Censo Escolar. 


\section{http://dx.doi.org/10.5902/1984686X39687}

${ }^{11}$ Considerando alunos com deficiências, TGD e altas habilidades/superdotação. A expressão "aluno incluído" nos remete aos estudantes com NEEs, sendo utilizada nos documentos divulgados pelo INEP referentes ao desempenho das escolas na Prova Brasil de 2013.

${ }^{12}$ De acordo com o relato da equipe, tratava-se de um aluno com deficiência intelectual leve associada aos distúrbios de aprendizagem.

${ }^{13}$ Neste caso, também era um estudante com deficiência intelectual.

${ }^{14}$ Aqui a entrevistada faz referência à Avaliação Nacional da Educação Básica (ANEB) amostral, aplicada na escola no ano de 2015.

${ }^{15}$ Quando menciona as dificuldades do aluno, ela se refere à aquisição da escrita e à compreensão integral de textos extensos. Salientamos que este mesmo aluno (com o auxílio da profissional de apoio à inclusão) se saiu bem em outra avaliação diagnóstica realizada na escola. Contudo, seu bom desempenho gerou desconfianças na equipe gestora, em especial na diretora da Escola Helena Antipoff.

${ }^{16}$ Professora de apoio à inclusão do aluno em questão.

${ }^{17}$ Extinta em 02 de janeiro de 2019 pelo presidente Jair Messias Bolsonaro. Mais informações em Silva, Silva e Machado (no prelo).

${ }^{18}$ Retomando aqui a terminologia utilizada nos Relatórios Nominais referentes aos alunos com NEEs emitidos pela SEDUCE.

\section{Correspondência}

Erika Marinho Witeze - Instituto Federal de Educação, Ciência e Tecnologia de Goiás, IFG, Campus Anápolis, Av. Pedro Ludovico, s/n, Residencial Reny Cury, Anápolis, Goiás - Brasil.

CEP: $74055-110$

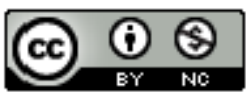

This work is licensed under a Creative Commons Attribution-NonCommercial 4.0 International (CC BY-NC 4.0) 